\title{
Metadehumanization erodes democratic norms during the 2020 presidential election 4
}

\author{
Alexander P. Landry (i) | Elliott Ihm | Spencer Kwit \\ Jonathan W. Schooler
}

Department of Psychological and Brain Sciences, University of California, Santa Barbara, California, USA

\section{Correspondence}

Alexander P. Landry, Department of Psychological and Brain Sciences, University of California, Santa Barbara, CA 931069660, USA.

Email:landry.alex1@gmail.com

This study was preregistered at the Open Science Framework (OSF) prior to data collection (https://osf.io/x549d). All materials, the preregistration manuscript, obtained data, and analyses codes are also available at the OSF storage (https://osf.io/d2g59/).

\begin{abstract}
The present research directly replicates past work suggesting that metadehumanization, the perception that another group dehumanizes your own group, erodes Americans' support for democratic norms. In the days surrounding the 2020 US Presidential Election, American political partisans perceived that their political opponents dehumanized them more than was actually the case. Partisans' exaggerated metadehumanization inspired reciprocal dehumanization of the other side, which in turn predicted their support for subverting democratic norms to hurt the opposing party. Along with replicating past work demonstrating metadehumanization's corrosive effect on democratic integrity, we also contribute novel insights into this process. We found the most politically engaged partisans held the most exaggerated, and therefore most inaccurate, levels of metadehumanization. Moreover, despite the socially progressive and egalitarian outlook traditionally associated with liberalism, the most liberal Democrats actually expressed the greatest dehumanization of Republicans. This suggests that political ideology can at times be as much an expression of social identity as a reflection of deliberative policy considerations, and demonstrates the need to develop more constructive outlets for social identity maintenance.
\end{abstract}


Modern egalitarian norms tend to discourage the expression of overt hostility toward social outgroups (e.g., racial, ethnic, and religious; Iyengar \& Westwood, 2015). Nonetheless, political partisans appear more than willing to explicitly derogate and discriminate against opposing partisans (see Iyengar et al., 2019 for a review). Partisans' prejudice toward their political opponents is at a 40-year high (Finkel et al., 2020; Iyengar et al., 2019). Americans are even willing to blatantly dehumanize their political opponents, rating them as subhuman apes or ascribing them animalistic traits (Cassese, 2019). This dehumanization goes beyond prejudice, as it predicts support for military aggression, discriminatory social policies, and even torturing members of the dehumanized group, over and above the effects of prejudice toward them (see Kteily \& Bruneau, 2017 for a review). In politics, dehumanization of opposing partisans is associated with spiteful behavior that hurts the other side at the expense of democratic integrity (Moore-Berg et al., 2020a).

In a nationally representative sample, Moore-Berg et al. (2020a) observed that Democrats and Republicans both dehumanized the other side, and did so to roughly equal degrees. That is, Democrats and Republicans both considered members of the opposing party about 21 points less human than their own party on a widely used measure of dehumanization (Figure 1; Kteily et al., 2015). However, Democrats and Republicans substantially overestimated just how much the other side dehumanized them. Namely, both sides believed that the other party considered them about 60 points less human, as opposed to the true value of 21 . The fact that partisans on both sides of the aisle thought their opponents dehumanized them 300\% more than they actually did is a striking instance of negativity bias in intergroup conflict, a tendency for people to have overly negative judgments about an outgroup's intentions (Lees \& Cikara, 2020).

This perception that another group dehumanizes your own group, metadehumanization, fuels intergroup hostility. Since we derive positive esteem from our membership in valued groups (Tajfel \& Turner, 1986), the perception that we are dehumanized by another group threatens our social identity (Branscombe et al., 1999). This experience of social identity threat inspires a desire to restore the ingroup's status by reciprocally denigrating the offending outgroup (Branscombe \& Wann, 1994). Therefore, metadehumanization leads to greater dehumanization of the outgroup because it inspires social identity threat and a desire to reciprocate this threat (Kteily et al., 2016; Landry et al., 2021). Dehumanization, in turn, promotes extreme hostility, which only fuels the conflict. Indeed, Moore-Berg et al. (2020a) found that partisans who felt dehumanized by the other side were more likely to reciprocally dehumanize them, which led to support for spiteful, antidemocratic measures to hurt the other side (e.g., using government institutions to shut down the opposing party's media outlets; Figure 2). It is important to note that metadehumanization

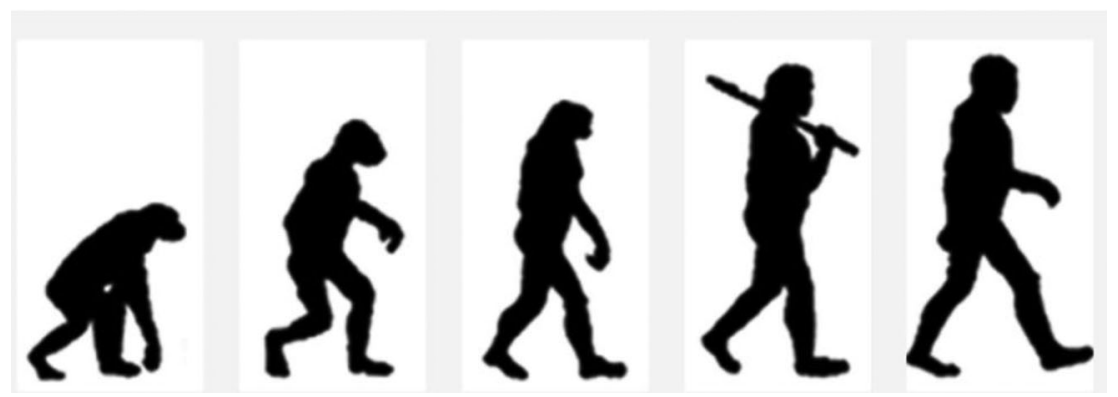

F I G U R E 1 “Ascent of Man” measure of dehumanization (Kteily et al., 2015). 
FIG URE 2 Metadehumanization model

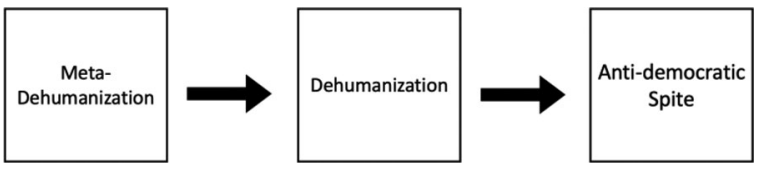

exerted this effect over and above partisans' perception that the other side was prejudiced toward them (i.e., metaprejudice). In fact, metadehumanization has been found to inspire greater hostility toward the offending outgroup than metaprejudice (Landry et al., 2021).

\section{The present research}

We sought to directly replicate Moore-Berg and colleagues' (2020a) investigation of (meta)dehumanization in the context of the 2020 US Presidential Election. Presidential elections make political identity more salient (Michelitch \& Utych, 2018) and contribute to partisan animosity by consistently denigrating the other side (Iyengar et al., 2012; Sood \& Iyengar, 2016). In fact, "across recent election cycles, people were $50-150 \%$ more affectively polarized by election day than they were a year earlier" (Iyengar et al., 2019, p. 135). The vitriol surrounding a presidential election may also increase partisans' dehumanization of the other side, as high levels of partisan dehumanization were documented in the days preceding the 2016 Presidential Election (Cassese, 2019).

The 2020 Presidential Election was particularly divisive, with gaping differences between Democrats and Republicans in their policy preferences and issue priorities (Deane \& Gramlich, 2020). These ideological differences were amplified by vitriolic media coverage and campaign advertising, with spending on the latter reaching historic proportions (Wesleyan Media Project, 2020). We aimed to determine whether, in line with Moore-Berg et al. (2020a), partisans continued to show a negativity bias in their metadehumanization during the 2020 Presidential Election, despite this being a particularly contentious political moment where partisans' "ground level" dehumanization of the opposition was likely to be high. We also aimed to replicate MooreBerg et al.'s (2020a) finding that metadehumanization predicted antidemocratic spite by inspiring reciprocal dehumanization (Figure 2). Since metadehumanization also foments hostility by inspiring prejudice toward the offending group (Landry et al., 2021), we examined prejudice as an additional mediator of metadehumanization's effect on spite. Finally, we accounted for metaprejudice, which also explains unique variance in partisan spite (Moore-Berg et al., 2020a), to isolate the effect of metadehumanization in our analyses. ${ }^{1}$

We collected data both immediately preceding, and after, the election results were finalized. This allowed us to directly replicate the design of Moore-Berg et al. (2020a), and to determine whether metadehumanization's effect on spite is durable over time. We expected to replicate the two major findings from this past research: that at both time points, partisans' metadehumanization would be greater than their political opponents' actual dehumanization (H1), and that

\footnotetext{
${ }^{1}$ We primarily focus on metadehumanization in the main text of this manuscript, as it appears to foment greater intergroup hostility than metaprejudice (Landry et al., 2021). Nonetheless, we also performed the same analyses for metaprejudice as we did for metadehumanization, and observed a largely analogous pattern of results (albeit with somewhat smaller effect sizes, in line with our notion that metadehumanization may be a particularly potent facilitator of hostility). Results concerning metaprejudice can be found in Supplementary Material 1 (see also Note 7).
} 
metadehumanization at Time 1 would predict spite at Time 2 through reciprocal dehumanization and prejudice (both measured at Time $1 ; \mathrm{H} 2$ ).

Additionally, we explored whether partisans' levels of political engagement were associated with their metadehumanization. Although political engagement may seem benign or even virtuous, Americans who report being most knowledgeable about politics are ironically the ones most likely to hold exaggerated stereotypes about their political opponents (Ahler \& Sood, 2018). Political misperceptions also increase with self-reported interest in politics and exposure to online news media (Enders \& Armaly, 2019; Yang et al., 2016). Therefore, although healthy democracies are predicated on a politically engaged citizenry (Dahl, 2020), we anticipated a perverse effect whereby the most engaged partisans would also have the most exaggerated metadehumanization.

\section{METHODS}

We report methods and results relevant to (meta)dehumanization and antidemocratic spite. However, we also explored other variables related to sociopolitical beliefs (e.g., system justification; Jost \& Andrews, 2011), and provide details regarding these additional measures and the full procedure in our preregistration on the Open Science Framework: https://osf.io/d2g59/. All measures are also available upon request. Moreover, given that we recruited participants who were preapproved by a participant-sourcing platform (see below), we did not employ additional exclusion criteria.

\section{Participants}

A power analysis using $G^{*}$ Power (Faul et al., 2007) determined that 542 participants per group were needed to detect a small effect $(d=0.2)$ of differences between partisans' metadehumanization and the other side's actual dehumanization of them with $95 \%$ power. We planned to deliberately oversample to account for attrition by recruiting 800 Democrats and 800 Republicans. However, we only succeeded in collecting data from 734 Democrats and 425 Republicans before the election results were finalized, after which we terminated our first wave of data collection. Of these participants, 543 Democrats and 318 Republicans responded at our follow-up (74\% retention; 81\% White, 7\% Black, 7\% Asian, 3\% Other; 56\% female; $M_{\text {age }}=40.80$ years; 63\% Democrat, 37\% Republican). A sensitivity analysis determined this sample size enabled us to detect an effect of $d=0.23$ with 95\% power (G*Power; Faul et al., 2007).

Participants were Amazon Mechanical Turk workers (MTurk; Buhrmester et al., 2018) preapproved by the participant-sourcing platform CloudResearch as being high-quality respondents (Littman et al., 2017).

\section{Measures}

\section{Dehumanization}

Participants were presented with the "Ascent of Man" image representing lay beliefs of evolutionary progress (Figure 1; Kteily et al., 2015). They were asked How evolved do you think each group is? and used slider scales ranging from 0 (Least Evolved) to 100 (Most Evolved) to rate Democrats and 
Republicans. We created a difference score (ingroup - outgroup) such that higher scores reflected greater dehumanization of the outgroup.

\section{Prejudice}

We used a feeling thermometer (Haddock et al., 1993) to measure partisans' prejudice toward the other side. Participants rated how they felt toward Democrats and Republicans using a slider scale ranging from 0 (Extremely Cold) and 100 (Extremely Warm). A difference score was created (ingroup - outgroup) such that higher scores reflected greater prejudice toward the outgroup.

\section{Metadehumanization and metaprejudice}

We followed Moore-Berg et al. (2020a) in modeling these measures after the prejudice and dehumanization measures. To measure metadehumanization, partisans indicated where they believed their political outgroup would place Democrats and Republicans on the Ascent measure of dehumanization. To measure metaprejudice, partisans indicated where their political outgroup would place Democrats and Republicans on the feeling thermometer. We calculated difference scores (how outgroup was perceived to rate outgroup - how outgroup was perceived to rate ingroup), such that higher scores reflect greater metadehumanization and metaprejudice.

\section{Antidemocratic spite}

We measured participants' willingness to hurt the other party by subverting democratic norms with six items adapted from Moore-Berg et al. (2020a; Democrats: Time 1/Time 2 as = .82/.83; Republicans: Time 1/Time 2 as $=.82 / .87$ ). Participants rated their agreement with items like [Political ingroup] should do everything they can to hurt the [political outgroup], even if it is at the shortterm expense of the country using a Likert scale ranging from 1 (Strongly disagree) to 7 (Strongly agree).

\section{Political ideology}

Following past research (Landry et al., 2021), participants were asked to Please indicate the extent to which you consider yourself to be liberal or conservative on most political and social issues and responded using a slider scale ranging from 0 (Extremely Liberal) to 100 (Extremely Conservative).

\section{Political interest, knowledge, and online media use}

Participants completed one-item measures of interest in politics (How interested in politics are you?), political knowledge (How knowledgeable about politics are you?), and online media use (How often do you visit websites or social media to get political news?) on Likert scales ranging from 1 (Not at all interested/Not at all knowledgeable/Never or almost never) to 5 (Extremely interested/Extremely knowledgeable/Daily). 
TA B L E 1 Descriptive statistics: metadehumanization and dehumanization

\begin{tabular}{lll}
\hline & Democrats & Republicans \\
\hline Dehumanization (Time 1) & $31.31(33.18)$ & $20.20(31.17)$ \\
Dehumanization (Time 2) & $28.40(31.36)$ & $20.75(32.57)$ \\
Metadehumanization (Time 1) & $50.24(37.38)$ & $51.62(36.31)$ \\
Metadehumanization (Time 2) & $48.46(36.05)$ & $51.41(34.68)$ \\
\hline
\end{tabular}

Note. Standard deviations in parentheses.

\section{Procedure}

We collected data at two time points, once right before the results of the election were finalized (October 30-November 7) and again right after the results were finalized (November 8-November 16). ${ }^{2}$ In the first wave of data collection, participants first provided information about their political ideology, interest, knowledge, and online news media use. They then evaluated Democrats and Republicans on the measures of dehumanization, prejudice, metadehumanization, and metaprejudice. The targets of evaluation (Democrats and Republicans) were presented in counterbalanced order on each measure, and the order of the measures was randomized. They then completed the measure of antidemocratic spite (items presented in randomized order), provided demographic information, and were informed they would be contacted again via the email address linked to their MTurk account after the election results were finalized. At follow-up, participants completed the exact same procedure, except this time we did not ask for demographic information or their political ideology, interest, knowledge, and online news media use.

\section{RESULTS}

\section{Partisans have exaggerated metadehumanization}

Consistent with past research (Cassese, 2019; Moore-Berg et al., 2020a), American partisans dehumanized their political outgroup (see Table 1 for descriptives). Nonetheless, we hypothesized that partisans expected the other side would dehumanize them more than they actually did (H1). Therefore, we conducted a series of independent samples $t$-tests ${ }^{3}$ that compared each side's metadehumanization with the other side's dehumanization, both before and after the election results were finalized. Indeed, in direct replication of Moore-Berg et al. (2020a), Democrats perceived Republicans to dehumanize them more than they actually did (Time $1: M_{\text {diff }}=30.04, t(859)$ $=12.08, p<.001, d=0.87$; Time $\left.2: M_{\text {diff }}=27.71, t(858)=11.27, p<.001, d=0.81\right)$, and Republicans perceived Democrats to dehumanize them more than they actually did (Time 1: $M_{\text {diff }}=20.31$,

\footnotetext{
${ }^{2}$ We considered the results finalized at the end of November 7, by which time the Associated Press, Fox News, and the other major networks announced Biden had exceeded the 270 electoral votes required to be named President-elect (Steinhauser $\&$ Singman, 2020). However, given that then-President Trump had not yet conceded at the time of Time 2 data collection, we also asked participants who they believed won the election. Eighty-three percent of participants reported thinking that Biden won (11\% reported "Not sure," and 6\% reported thinking Trump won). Restricting our analyses to only those who thought Biden won did not change the overall pattern of results.

${ }^{3}$ All analyses were performed with 1000 bootstrap resamples, expect those using the PROCESS macro (Hayes, 2018), which were performed with 5000 bootstrap resamples.
} 


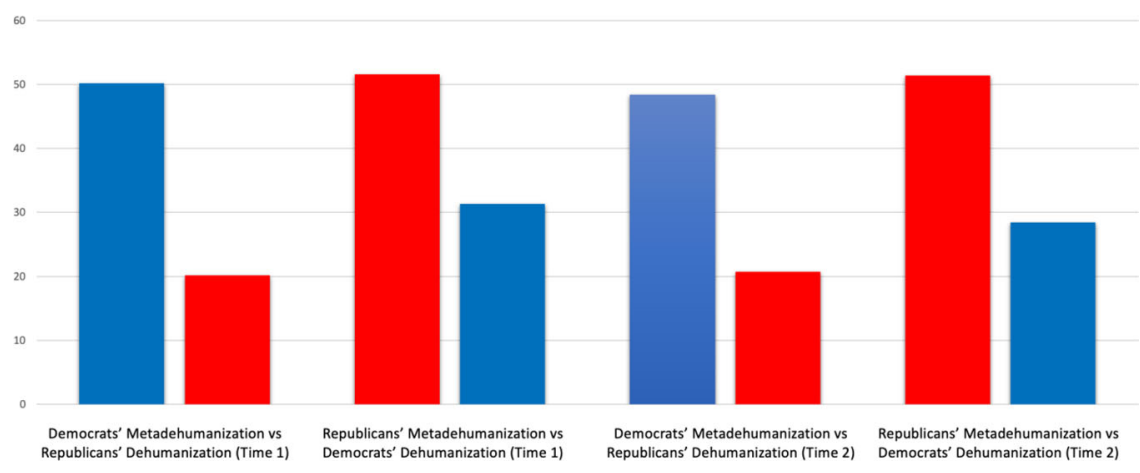

F I G U R E 3 Partisans' exaggerated metadehumanization. Note. Blue bars represent Democrats' scores on the (meta)dehumanization measures and red bars represent Republicans' scores [Color figure can be viewed at wileyonlinelibrary.com]

TA B LE 2 Mediation model variable intercorrelations

\begin{tabular}{lllll}
\hline Correlations & $\mathbf{1}$ & $\mathbf{2}$ & $\mathbf{3}$ & $\mathbf{4}$ \\
\hline 1. Dehumanization & - & & & \\
2. Metadehumanization & $.35^{* * *}$ & - & & \\
3. Prejudice & $.53^{* * *}$ & $.25^{* * *}$ & - & \\
4. Metaprejudice & $.22^{* * *}$ & $.39^{* * *}$ & $.32^{* * *}$ & - \\
5. Spite & $.36^{* * *}$ & $.17^{* * *}$ & $.37^{* * *}$ & $.12^{* * *}$ \\
\hline
\end{tabular}

${ }^{* * *} p \leq .001$.

$t(859)=8.37, p<.001, d=0.58$; Time $\left.2: M_{\text {diff }}=23.01, t(858)=9.99, p<.001, d=0.70\right)$. These results are depicted in Figure 3.

\section{Metadehumanization predicts spite through reciprocal dehumanization}

We then tested our second hypothesis, that metadehumanization would inspire spite through reciprocal dehumanization and prejudice $(\mathrm{H} 2)$, with a parallel mediation using the PROCESS macro (Model 4; Hayes, 2018). Metadehumanization was entered as the predictor, dehumanization and prejudice were the mediators, and spite was the outcome. We also included metaprejudice as a covariate to isolate the effect of metadehumanization, as both explain unique variance in partisan spite (Moore-Berg et al., 2020a). All variables were measured at Time 1, expect for spite (which was measured at Time 2). ${ }^{4}$ Intercorrelations between all variables in this model are presented in Table 2.

Again replicating Moore-Berg et al. (2020a), metadehumanization exerted an indirect effect on antidemocratic spite through reciprocal dehumanization, $\beta_{\text {indirect }}=.07, S E=.02,95 \% \mathrm{CI}[.04$, .11]. Metadehumanization's effect on spite was also mediated by prejudice, $\beta_{\text {indirect }}=.04, S E=$ $.01,95 \% \mathrm{CI}[.02, .06]$. After taking these mediators into account, metadehumanization exerted no

\footnotetext{
${ }^{4}$ We conducted two analogous mediation models with all the variables measured at the same time point (i.e., one model with all the variables measured before the election results were finalized, and a second with all the variables measured after). For both models, the results remained virtually unchanged to those reported here.
} 


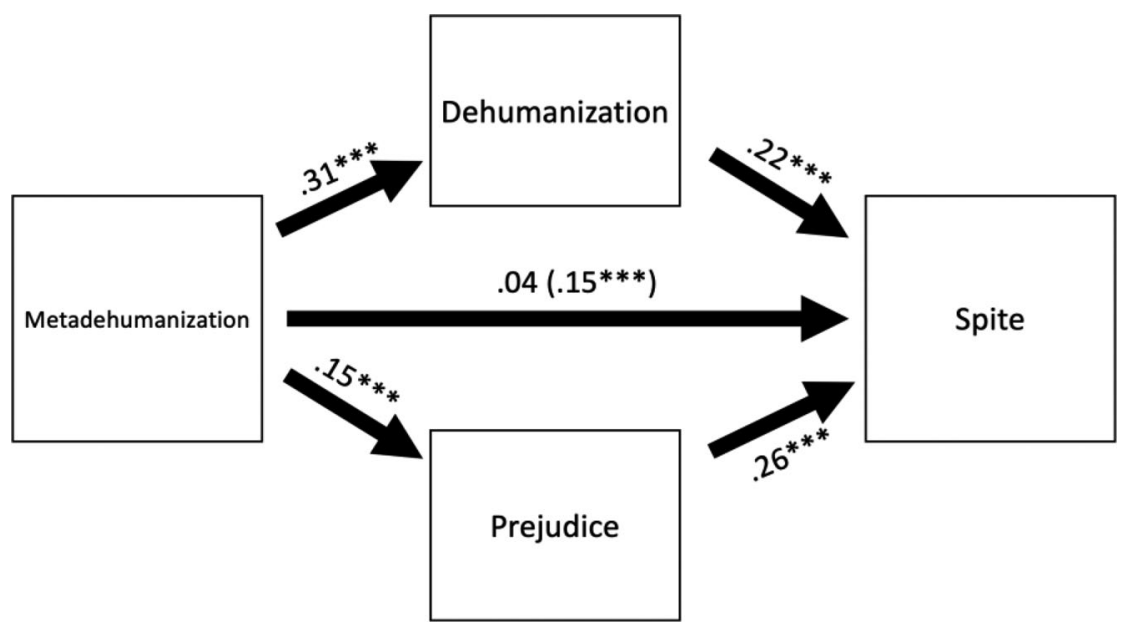

F I G U R E 4 Path model showing effects of Time 1 metadehumanization on Time 2 spite, mediated by Time 1 dehumanization and prejudice. Note. Numbers reflect standardized beta coefficients $* * * p<.001$

direct effect on spite, suggesting full mediation by dehumanization and prejudice (see Figure 4 for path model). ${ }^{5}$

\section{Exploratory analyses}

\section{Factors associated with metadehumanization}

Bivariate correlations revealed weak positive relationships between partisans' metadehumanization and their political interest (Time $1: r=.14, p<.001$; Time $2: r=.09, p=.009$ ), knowledge (Time 1: $r=.14, p<.001$; Time 2: $r=.12, p<.001$ ), and use of online media (Time 1: $r=.10, p=$ .004 ; Time $2: r=.10, p=.004)$.

\section{Ideological correlates of dehumanization}

Ideological conservatism tends to predict dehumanization (e.g., Bruneau et al., 2018; Kteily et al., 2015), presumably because conservatives favor group-based dominance and status maintenance (Moore-Berg et al., 2020b). Indeed, when we restricted our sample to Republicans, conservatism predicted their dehumanization of Democrats (Time 1: $r=.40, p<.001$; Time 2: $r=.37, p<$ .001). However, when we analyzed Democrats' dehumanization of Republicans, the opposite trend emerged. For Democrats, the strength of their liberal ideology (represented by lower values on the liberal-conservative scale) predicted greater dehumanization of Republicans (Time 1: $r=-.19, p<.001$; Time $2: r=-.21, p<.001)$.

\footnotetext{
${ }^{5}$ We conceptually replicated these results with an additional outcome measure also shown to undermine bipartisan relations, the desire for distance from the other side (Barber \& McCarty, 2016). See Supplementary Material 2 for the reporting of these results
} 


\section{Partisan differences in (meta)dehumanization and spite}

Moore-Berg et al. (2020a) found roughly equal levels of both metadehumanization and dehumanization between Democrats and Republicans. Consistent with this, independent samples $t$-tests revealed that Democrats and Republicans did not differ in their metadehumanization (Time 1: $p$ $=.63$; Time $2: p=.20) .{ }^{6}$ However, in our sample, Democrats expressed greater dehumanization of Republicans than vice-versa (Time $1: M_{\text {diff }}=11.14, t(858)=4.86, p<.001, d=0.35$; Time $2: M_{\text {diff }}$ $=7.65, t(858)=3.41, p=.002, d=0.24)$. Democrats also expressed greater antidemocratic spite than Republicans (Time 1: $M_{\text {diff }}=0.39, t(853)=4.72, p<.001, d=0.33$; Time $2: M_{\text {diff }}=0.31, t(853$ ) $=3.68, p=.002, d=0.26)$.

\section{DISCUSSION}

Animosity between Democrats and Republicans is at a 40-year high (Iyengar et al., 2019), and seemingly intractable polarization is eroding democratic norms (Barber \& McCarty, 2016). MooreBerg and colleagues (2020a) found that this is in part due to partisans' overly negative perception about the degree to which their political opponents dehumanize them (i.e., exaggerated metadehumanization), inspiring us to investigate metadehumanization's role in interpartisan hostility during the 2020 US Presidential Election. We replicated their major findings: American partisans reported exaggerated metadehumanization in the days surrounding the election, and this exaggerated metadehumanization predicted greater reciprocal dehumanization, which in turn predicted antidemocratic spite (Figure 2). This process occurred for both Democrats and Republicans, and was robust to changes in political power dynamics as it emerged both immediately before and after the election. Taken together with previous evidence demonstrating metadehumanization's causal role in fomenting hostility (Landry et al., 2021), finding a way to disrupt this corrosive process is paramount.

One promising means to dampen partisans' exaggerated metadehumanization lies in addressing potential precursors to it. We found an ironic effect whereby those who were most politically engaged also had the most extreme (and therefore inaccurate) metadehumanization. This may be because those engaged with partisan media are more frequently exposed to outspoken and polarized party elites (Yang et al., 2016). This exposure to elite polarization fosters a "zero sum” political environment that signals the other party poses a social identity threat (Banda \& Cluverius, 2018). Perhaps interventions that buffer against social identity threat, such as collective affirmations (Sherman et al., 2007), could mitigate the downstream effects of elite polarization. Future work should consider this when investigating how exposure to elite polarization influences partisans' metadehumanization.

Given that metadehumanization exerted its effect on spite in large part through dehumanization, examining factors contributing to the latter is also crucial. Previous research has found that ideological liberalism may serve as a buffer against dehumanization, as it traditionally reflects a commitment to progressive notions of egalitarianism (e.g., Bruneau et al., 2018; see Moore-Berg et al., 2020b). However, we found that the most liberal Democrats expressed the greatest dehumanization of Republicans. This counterintuitive finding may be explained if American political

\footnotetext{
${ }^{6}$ Also in line with Moore-Berg et al. (2020a), Democrats and Republicans did not differ in their metaprejudice (Time 1: $p$ $=.20$; Time $2: p=.52)$. However, Democrats did report greater prejudice than Republicans (Time $1: M_{\mathrm{diff}}=15.30, t(858)=$ $6.54, p<.001, d=0.45$; Time $\left.2: M_{\mathrm{diff}}=13.21, t(858)=5.61, p<.001, d=0.39\right)$.
} 
affiliation is based on a "moralized identification with one political group and against another," more akin to tribal sectarianism than well-reasoned differences in ideological preference (Finkel et al., 2020, p. 533). Liberals and conservatives have increasingly sorted into their respective Democratic and Republican parties (Finkel et al., 2020), such that where one falls on the liberalconservative continuum serves as a salient marker of political identity (Mason, 2018). ${ }^{7}$ Since denigrating competitive outgroups also bolsters one's social identity (Tajfel \& Turner, 1986), for highly identified Democrats, expressions of their adherence to liberalism and dehumanization of Republicans may go hand in hand.

We also found that Democrats expressed more dehumanization and antidemocratic spite toward Republicans than vice-versa. Again, this appears to clash with research suggesting that liberals are more open, tolerant, and less biased toward outgroup members (see Jost, 2017 for a review). However, recall that exposure to polarizing political elites inspires social identity threat and animosity toward the opposing side (Banda \& Cluverius, 2018). Perhaps the Trump administration's divisive rhetoric and antiegalitarian social policies (e.g., Mason et al., 2020)) led Democratic liberals to feel particularly threatened. This experience of social identity threat could then promote their dehumanization of Republicans (Kteily et al., 2016; Landry et al., 2021). Again, interventions that palliate partisans' experience of social identity threat warrant further investigation.

Despite these insights, the present design was subject to several limitations. Although MTurk workers are comparable to the general US population on key dimensions of political ideology (Clifford et al., 2015), they are not truly representative. Particularly problematic is the fact that we recruited a larger proportion of Democrats (63\% of the sample) than Republicans (37\%). However, we are confident in the generality of our primary hypothesis tests, as they directly replicate those of Moore-Berg et al. (2020a), who recruited a representative sample of Democrats and Republicans. Nonetheless, our exploratory analyses, particularly the finding that Democrats expressed greater dehumanization and spite toward Republicans than vice-versa, should be interpreted with caution.

Partisans' misperceptions of their political opponents initiates a positive feedback loop of reciprocal animosity, which reinforces overly negative perceptions (Hetzel \& Laurin, 2020). This contributes to intractable partisan conflict and destabilizes American democracy (Barber \& McCarty, 2016). However, Americans on both sides of the aisle are becoming increasingly concerned by the divisive state of the country's politics (e.g., Pew Research Center, 2019). Those seeking to dampen partisan enmity could leverage corrective information interventions to attenuate their overly negative metadehumanization (Lees \& Cikara, 2020). They might also target potential antecedents of metadehumanization (e.g., elite polarization in media) or offer defense against its social identitythreatening consequences (e.g., via collective affirmation; Sherman et al., 2007) to cut off a feedback loop of mutual hostility that erodes democratic norms. Ultimately, we hope these insights lay the foundation for a future in which political disagreement coexists with mutual acceptance and productive bipartisanship.

\section{ACKNOWLEDGMENTS}

This study was preregistered on the Open Science Framework(OSF) prior to data collection (https: //osf.io/x549d) and the data and syntax are available on OSF storage (https://osf.io/d2g59/). The

\footnotetext{
${ }^{7}$ Indeed, $92.3 \%$ of Democrats reported being liberal (scoring below the midpoint on the 100-point scale of liberalconservative ideology), while $93.1 \%$ of Republicans reported being conservative. Moreover, Democrats' party identification was moderately correlated with their liberal ideology, $r=-.41, p<.001$, while Republicans' party identification was strongly correlated with their conservative ideology, $r=.71, p<.001$.
} 
University of California, Santa Barbara's institutional review board approved this study (protocol \# 176-20-0747), and this work was supported by a grant from the University of California, Santa Barbara.

\section{CONFLICTS OF INTEREST}

The authors declare that there are no conflicts of interest.

\section{OPEN RESEARCH BADGES}

11 This article has earned Open Data and Preregistered Research Design badges. Data and the preregistered design and analysis plan are available at https://osf.io/d2g59/ and https://osf.io/ x549d.

\section{O R C I D}

\section{Alexander P. Landry (D) https://orcid.org/0000-0003-1579-7326}

\section{R EF E R EN C ES}

Ahler, D.J. \& Sood, G. (2018) The parties in our heads: Misperceptions about party composition and their consequences. Journal of Politics, 80(3), 964-981. https://doi.org/10.1086/697253

Banda, K.K. \& Cluverius, J. (2018) Elite polarization, party extremity, and affective polarization. Electoral Studies, 56, 90-101. https://doi.org/10.1016/j.electstud.2018.09.009

Barber, M. \& McCarty, N. (2016) Causes and consequences of polarization. In (J. Mansbridge \& C. J. Martin Eds.), Political negotiation: A handbook (pp. 37-90). Washington, DC: Brookings Institution Press.

Branscombe, N.R. \& Wann, D.L. (1994) Collective self-esteem consequences of outgroup derogation when a valued social identity is on trial. European Journal of Social Psychology, 24(6), 641-657. https://doi.org/10.1002/ejsp. 2420240603

Branscombe, N.R., Ellemers, N., Spears, R. \& Doosje, B. (1999) The context and content of social identity threat. In (N. Ellemers, R. Spears, \& B. Doosje Eds.), Social identity: Context, commitment, content (pp. 35-58). Blackwell Science.

Bruneau, E., Kteily, N. \& Laustsen, L. (2018) The unique effects of blatant dehumanization on attitudes and behavior towards Muslim refugees during the European 'refugee crisis' across four countries. European Journal of Social Psychology, 48(5), 645-662. https://doi.org/10.1002/ejsp.2357

Buhrmester, M.D., Talaifar, S. \& Gosling, S.D. (2018) An evaluation of Amazon's Mechanical Turk, its rapid rise, and its effective use. Perspectives on Psychological Science, 13(2), 149-154. https://doi.org/10.1177/1745691617706516

Cassese, E.C. (2019) Partisan dehumanization in American politics. Political Behavior, 1-22. https://doi.org/10.1007/ s11109-019-09585-2

Clifford, S., Jewell, R.M. \& Waggoner, P.D. (2015) Are samples drawn from Mechanical Turk valid for research on political ideology? Research \& Politics, 2(4). https://doi.org/10.1177/2053168015622072

Dahl, R.A. (2020) On democracy. Yale University Press.

Deane, C. \& Gramlich, J. (2020) 2020 election reveals two broad voting coalitions fundamentally at odds. Pew Research Center. Accessed on 14 January 2021. Available at: https://www.pewresearch.org/fact-tank/2020/11/ 06/2020-election-reveals-two-broad-voting-coalitions-fundamentally-at-odds/

Enders, A.M. \& Armaly, M.T. (2019) The differential effects of actual and perceived polarization. Political Behavior, 41(3), 815-839. https://doi.org/10.1007/s11109-018-9476-2

Faul, F., Erdfelder, E., Lang, A.G. \& Buchner, A. (2007) G* Power 3: A flexible statistical power analysis program for the social, behavioral, and biomedical sciences. Behavior Research Methods, 39(2), 175-191. https://doi.org/ 10.3758/BF03193146

Finkel, E.J., Bail, C.A., Cikara, M., Ditto, P.H., Iyengar, S., Klar, S., et al. (2020) Political sectarianism in America. Science, 370(6516), 533-536. https://doi.org/10.1126/science.abe1715 
Haddock, G., Zanna, M.P. \& Esses, V.M. (1993) Assessing the structure of prejudicial attitudes: The case of attitudes toward homosexuals. Journal of Personality and Social Psychology, 65(6), 1105-1118. https://doi.org/10.1037/ 0022-3514.65.6.1105

Hayes, A.F. (2018) Introduction to mediation, moderation, and conditional process analysis: A regression-based approach (2nd ed.). Guilford Press.

Heltzel, G. \& Laurin, K. (2020) Polarization in America: Two possible futures. Current Opinion in Behavioral Sciences, 34, 179-184. https://doi.org/10.1016/j.cobeha.2020.03.008

Iyengar, S. \& Westwood, S.J. (2015) Fear and loathing across party lines: New evidence on group polarization. American Journal of Political Science, 59(3), 690-707. https://doi.org/10.1111/ajps.12152

Iyengar, S., Lelkes, Y., Levendusky, M., Malhotra, N. \& Westwood, S.J. (2019) The origins and consequences of affective polarization in the United States. Annual Review of Political Science, 22, 129-146. https://doi.org/10. 1146/annurev-polisci-051117-073034

Iyengar, S., Sood, G. \& Lelkes, Y. (2012) Affect, not ideology: A social identity perspective on polarization. Public Opinion Quarterly, 76(3), 405-431. https://doi.org/10.1093/poq/nfs038

Jost, J.T. (2017) Ideological asymmetries and the essence of political psychology. Political Psychology, 38(2), 167-208.

Jost, J.T. \& Andrews, R. (2011) System justification theory. Encyclopedia of Peace Psychology, https://doi.org/10. 1002/9780470672532.wbepp273

Kteily, N.S. \& Bruneau, E. (2017) Darker demons of our nature: The need to (re) focus attention on blatant forms of dehumanization. Current Directions in Psychological Science, 26(6), 487-494. https://doi.org/10.1177/ 0963721417708230

Kteily, N., Bruneau, E., Waytz, A. \& Cotterill, S. (2015) The ascent of man: Theoretical and empirical evidence for blatant dehumanization. Journal of Personality and Social Psychology, 109(5), 901-931. https://doi.org/10.1037/ pspp0000048

Kteily, N., Hodson, G. \& Bruneau, E. (2016) They see us as less than human: Metadehumanization predicts intergroup conflict via reciprocal dehumanization. Journal of Personality and Social Psychology, 110(3), 343-370. https://doi.org/10.1037/pspa0000044

Landry, A. Ihm, E. \& Schooler, J.W. (2021) Hated but still human: Metadehumanization leads to greater hostility than metaprejudice. Group Processes \& Intergroup Relations, https://doi.org/10.1177/1368430220979035

Lees, J. \& Cikara, M. (2020) Inaccurate group meta-perceptions drive negative out-group attributions in competitive contexts. Nature Human Behaviour, 4(3), 279-286. https://doi.org/10.1038/s41562-019-0766-4

Litman, L., Robinson, J. \& Abberbock, T. (2017) TurkPrime. com: A versatile crowdsourcing data acquisition platform for the behavioral sciences. Behavior Research Methods, 49(2), 433-442. https://doi.org/10.3758/ s13428-016-0727-z

Mason, L. (2018) Uncivil agreement: How politics became our identity. University of Chicago Press.

Mason, L., Wronski, J. \& Kane, J.V. (2020) Trump support is not normal partisanship. New America. Available at: https://www.newamerica.org/political-reform/reports/political-parties-good-for/trump-supportis-not-normal-partisanship/ (Accessed on January 17, 2021).

Michelitch, K. \& Utych, S. (2018) Electoral cycle fluctuations in partisanship: Global evidence from eighty-six countries. Journal of Politics, 80(2), 412-427. https://doi.org/10.1086/694783

Moore-Berg, S.L., Ankori-Karlinsky, L.O., Hameiri, B. \& Bruneau, E. (2020a) Exaggerated meta-perceptions predict intergroup hostility between American political partisans. Proceedings of the National Academy of Sciences, 117(26), 14864-14872. https://doi.org/10.1073/pnas.2001263117

Moore-Berg, S.L., Hameiri, B. \& Bruneau, E. (2020b) The prime psychological suspects of toxic political polarization. Current Opinion in Behavioral Sciences, 34, 199-204. https://doi.org/10.1016/j.cobeha.2020.05.001

Pew Research Center. (2019) Public highly critical of state of political discourse in the U.S. Accessed on 14 January 2021. Available at: https://www.pewresearch.org/politics/2019/06/19/public-highly-critical-of-state-ofpolitical-discourse-in-the-u-s/

Sherman, D.K., Kinias, Z., Major, B., Kim, H.S. \& Prenovost, M. (2007) The group as a resource: Reducing biased attributions for group success and failure via group affirmation. Personality and Social Psychology Bulletin, 33(8), 1100-1112. https://doi.org/10.1177/0146167207303027

Sood, G. \& Iyengar, S. (2016) Coming to dislike your opponents: The polarizing impact of political campaigns. https://doi.org/10.2139/ssrn.2840225 
Steinhauser, P. \& Singman, B. (2020) Biden wins presidency, Trump denied second term in White House, Fox News projects. Fox News. Available at: https://www.foxnews.com/politics/biden-wins-presidency-trump-foxnews-projects (Accessed on January 19, 2021).

Tajfel, H. \& Turner, J.C. (1986) The social identity theory of inter-group behavior. In (S. Worchel \& W. Austin Eds.), Psychology of intergroup relations (pp. 7-24). Nelson Hall.

Wesleyan Media Project. (2020) Presidential general election ad spending tops \$1.5 billion. Accessed on 12 January 2021. Available at: https://mediaproject.wesleyan.edu/releases-102920/

Yang, J., Rojas, H., Wojcieszak, M., Aalberg, T., Coen, S., Curran, J., et al. (2016) Why are "others" so polarized? Perceived political polarization and media use in 10 countries. Journal of Computer-Mediated Communication, 21(5), 349-367. https://doi.org/10.1111/jcc4.12166

\section{AUTHOR BIOGRAPHIES}

Alexander P. Landry is an incoming graduate student at Stanford's Graduate School of Business. In 2020, he earned his Bachelor's degree at the University of California, Santa Barbara (UCSB), where he studied the social psychology of intergroup conflict under the tutelage of Dr. Jonathan Schooler.

Elliott Ihm earned his BS in Psychology from Northern Illinois University in 2014. He is currently a graduate student at UCSB, where he studies peak experiences, neuroplasticity, affective neuroscience, and the nature of consciousness.

Spencer Kwit is an undergraduate at UCSB.

Jonathan Schooler is a Professor of Psychology at UCSB. He earned his BA at Hamilton College in 1981 and his Ph.D. at the University of Washington in 1987. Jonathan pursues research on consciousness, memory, the relationship between language and thought, creativity, problem solving, decision making, and dehumanization.

\section{SUPPORTING INFORMATION}

Additional supporting information may be found online in the Supporting Information section at the end of the article.

How to cite this article: Landry A. P., Ihm E., Kwit S., Schooler J. W. et al. (2021) Metadehumanization erodes democratic norms during the 2020 presidential election. Anal Soc Issues Public Policy. 1-13. 